\title{
COMMENTARY
}

\section{Medical humanities: a vision and some cautionary notes}

\section{R S Downie}

J Med Ethics: Medical Humanities 2003;29:37-38

Stephen Pattison outlines his vision for medical humanities and then offers cautionary notes on what might go wrong with the movement. These notes are based on what he holds has already gone wrong with medical ethics, dramatically described as the "death course of a discipline". I have a great deal of sympathy both with his anxieties about the future development of medical humanities and with his critique of medical ethics. My reasons in both cases are a little different from his, and indeed part of his vision for medical humanities constitutes part of my worries about its future! I shall begin with some comments on Pattison's views on medical humanities, and then more briefly comment on his diagnosis of the ills of medical ethics.

Correspondence to: Professor R S Downie, Department of Philosophy, The University, Glasgow, Scotland; R.Downie@ philosophy.arts.gla.ac.uk

Accepted for publication 12 January 2003
$\mathrm{P}$ attison begins his account of his vision by observing that the medical humanities movement "does not yet have a fixed identity and form". We should note at the start, however, that the term "medical humanities" tends to be used in both a wide and a narrow sense. In its wider sense it consists of three movements which may overlap, but are distinct in their aims, methodologies, and participants. There is first what we may term "the arts as therapy". This is perhaps the oldest strand, for the use of music or the graphic arts or creative writing, has been around for many years as a recognised part of health care. Secondly, and more recently, community arts movements have made alliances with community health and health promotion movements. There have been successful ventures in some inner cities and socially deprived areas.

I think that Pattison wishes to include these movements under the umbrella of "medical humanities", for the first bullet point in his vision refers to his desire to "affirm and promote the place, importance and practice of humanities disciplines and arts in health and social care (performance)". But if he is including the "arts as therapy" and "community arts and health" as part of the medical humanities movement, then I think he can relax about their future. The reason is that the participants or professionals in these movements are, as it were, in gear. They are of necessity working with other professionals in their respective fields and are coming up against the realities of social deprivation and sick and dying patients. Such realities prevent the formation of any academic dogma.

There is, however, a third strand in the medical humanities movement-the use of the arts and humanities in the education of medical and nursing students and postgraduates. Sometimes the term "medical humanities" is used in a narrow sense to refer just to this movement, and the first two strands are given other names, such as "arts and health". But whether we use the term "medical humanities" in a wide or a narrow sense it is in the educational context that Pattison's fears are reasonably grounded. In general terms his fears concern the growth of an exclusive elite of those who profess medical humanities. That certainly is a danger, but I think it is possible to be more specific than he is.

More specifically let us consider undergraduate medical training. The first danger for the medical humanities comes from the enthusiasts, who would wish to see compulsory modules on the humanities for all medical students. This would be a complete disaster. Such courses would be received with resentment by medical students and be just one more chore to be got through. Moreover, who would teach, facilitate or tutor on such courses? The chances are that the teachers would be those who had attended a three day course (as for medical ethics), and the result would be quarterbaked teachers addressing resentful students. The first moral then is that the humanities must remain as Special Study Modules (SSMs) - that is, short, voluntary courses available to those with that kind of interest, and, if this can be managed, taught by those with a humanities background.

The second danger comes from the medical authorities, who have a tendency to look for measurable outcomes, and otherwise wish to force the humanities into some sort of inappropriate packaging. This must be resisted. If medical faculties wish to recognise the humanities as SSMs they must also accept the methods and approach of the humanities. Pattison rightly stresses this point, but he makes things hard for himself by using the terminology of the "instrumental" and the "intrinsic". As academic disciplines, history or literature or philosophy should be seen simply as components of a well rounded education. Do doctors wish to be broadly educated, or simply narrowly trained?

I shall develop the above point by referring to a third, and perhaps the most important, danger for the medical humanities. Indeed, its danger is so insidious that it has crept in as part of Pattison's "vision"! The danger lies in the very term "medical humanities". I appreciate that the term is here to stay, but it can give rise to two sorts of misunderstanding: the first derives from the word "medical", and the second from the word "humanities".

The first point is that the term "medical" is apt to suggest that SSMs should necessarily have a direct bearing on the practice of medicine. At its most absurd this becomes the insistence that the novels studied or the paintings looked at must 
have a doctor in them, or be by a doctor. But it is precisely this limited view of the world that the medical humanities should be correcting. What is important is to emphasise to medical students that there are ways of seeing the world other than the medical, that there are other rational methodologies for reaching the truth, and that there are truths about people and their behaviour which are not revealed by classes on "communication skills"-for example. Medical training - for that is what it is-is of necessity narrowly focused. The humanities can provide at least a hint that there are many other points of view.

The second danger is in the use of the word "humanities", for this suggests to many people that doctors lack humane qualities, and that this lack can be filled by studying the "humanities". These assumptions are pervasive in the medical humanities literature, including Pattison's paper. But speaking as a practitioner of the humanities I cannot honestly say that I find doctors any less humane than my colleagues in an arts and theology faculty.

The other point is equally absurd. Supposing medical students or doctors lack humane qualities I hardly think that these are likely to be supplied by reading a few novels, anymore than by attending a course on communication skills.

The term "humanities" originally meant the study of language and literature, especially the ancient classics, although it has now been extended to include most of the subjects studied in a typical faculty of arts. There is not the slightest evidence that such studies make people more "humane" in the sense of "compassionate", although it is likely that through the condensed experience of life in literature (or other arts) people may acquire a broader vision. Pattison rightly stresses the importance of this side to the humanities. I appreciate that we are now stuck with the term "medical humanities", and just hope that it is the "humanities" side rather than the medical side which is stressed in the delivery of courses. If the humanities are delivered to volunteers, preferably jointly taught by a humanities specialist and an interested doctor, then I do not think that Pattison's fears will be realised. The humanities can offer a modest but definite contribution to the making of a doctor.
I shall finish with a brief word on Pattison's pessimism about medical ethics. He is well aware that medical ethics is a growth industry, and what he deplores is the narrowing and specialisation of it, and its severance from broader considerations of health and medicine in the whole scheme of things. Are his criticisms justified?

Take first the developing research side to medical ethics. Narrowing and specialisation are inevitable as the subject develops, and are to be applauded rather than deplored. At the cutting edge the subject is moving away from the bland generalities of the "four principles" into the hard details of new medical advances. Turning now to undergraduate teaching I believe he is wrong to claim that there is an "agreed curricula for students and trainees". Some medical schools still force students into the mould of the "four principles", and others provide garbled accounts of philosophical theories. What in fact is needed as a bare minimum is knowledge of the General Medical Council (GMC) guidance on such matters as consent, best interests, confidentiality, withholding and withdrawing treatment, and who has the right to make decisions if the patient is incompetent. My own experience is that medical students, and often their seniors, are not well informed on such matters. Here I think the position is quite different from that of the medical humanities; all students and doctors should know the views of their governing body.

Turning thirdly to the claim that medical ethics has cut itself off from broader issues of life and death I think Pattison is right here. One problem is the use of the term "medical ethics" or "bioethics" or even "philosophical medical ethics", which restricts the scope of discussion to practical problems or ethical theories. If we were to see "medical ethics" as one aspect of a broader "philosophy of medicine" then its links with wider issues might be restored. Practitioners of the medical humanities are well placed to explore other approaches to medical ethics, and to hook them on to broader visions of life, as rightly desired by Pattison. Perhaps then, through the philosophy of medicine, the humanities will become the saviour of medical ethics. 